\title{
Motivation to Contribute
}

\section{I4.I Background}

If we think CI can benefit society, we need to understand how we can motivate individuals to engage in this type of collective problems solving. However, because CI covers such a broad area, including science, practical problem solving, and politics, this is a daunting task. Depending on the complexity of the task, the required skill level varies a lot. It ranges from innovation contests that often look for individuals with specific formal qualifications to citizen science projects that require simple image detection skills (e.g., Galaxy Zoo).

Furthermore, studies of motivation in peer-production communities identify a mixture of motivations, such as social status, peer effects, prosocial altruism, and group identification. Single individuals are motivated by a combination of different factors, and this mix will also vary (Benkler et al., 2015). Some citizen projects target specific groups who have advanced skills. This group has a strong intrinsic motivation if the activities are closely aligned with their needs and interests. However, it may be difficult to include volunteers with both high and low skills in the same project (Hecker et al., 20I8). One exception is Wikipedia, which has managed to offer a wide range of tasks at different skill levels. In innovation contests, prize money will obviously be important, but other intrinsic motivational factors are also influential (Baltzersen, 2020). Studies of open source software communities (FLOSS) have shown that it is possible to combine paid and unpaid contributions without excluding intrinsic motivational factors (Benkler et al., 2015).

Still, most of the CI projects in this book typically center on noneconomic motivational factors. In a historical perspective, we have more spare time than ever before (Shirky, 20Io). Many CI projects depend on this extra "time resource" because they rely on volunteering. However, the 
competition is fierce, from both social media and a range of entertainment services such as games and movies.

Motivational factors may also change over time. For example, in the original hackathons, individuals were highly motivated by the idea that they could produce something of value to everyone. However, in a recent study of a hackathon, only one third participated because they wanted to change the world ( 38 percent) to become a better place. Other motivational factors, like learning and networking or receiving recognition, were more important. It illustrates that motivation may change over time with each new generation (Briscoe \& Mulligan, 2014).

Since CI covers so many different practices, some claim that it is impossible to describe CI motivation within a single coherent motivational framework (Benkler et al., 2015). However, a tentative model can still be useful as a guide to provide an overview of various motivational factors that are important. In this chapter, the following factors are discussed:

- Being immersed

- Being recognized

- Being part of a community

- Learning as motivation

- Economic motivation

- Making societal contributions

These factors are inspired by a typology developed by Baltzersen (2020) in relation to online innovation contests. Solver statements about their motivation to participate in online innovation contests are an important part of the content in this chapter. These data may be somewhat biased in the sense that they highlight positive motivational factors, since the stories have been published openly. However, because many of the profile stories display authentic names or usernames, there is no reason to believe that the published content is untrue. However, the demographic background of the participants is also very similar, a vast majority being male, middleaged, and with highly qualified expertise. In addition, there are few examples from the political domain in this chapter.

\subsection{Being Immersed}

\section{I4.2.I Being Immersed in Simple Tasks}

If we look at motivational factors in different CI projects, it can be relevant to distinguish between low-level and high-level cognitive challenges. In CI 
projects, there is a wide range of relatively simple tasks. This can be an image recognition task in a citizen science project, rating the quality of a video on YouTube, fixing spelling errors in a Wikipedia article, stating your opinion in an argument map, or betting on the outcome of a political event in a prediction market. Most individuals can do these microtasks, and it will usually require a minimum of time and effort. Because they are simple, this increases the likelihood of getting more people to contribute.

These microtasks require a lower level of concentrated effort and can be done to relieve boredom for a brief period. Although most people may perceive an image recognition task on Galaxy Zoo as uninteresting, astronomy hobbyists enjoy this type of activity. Gamification designs can motivate individuals to do more repetitive tasks. In prediction markets, it is easy to place a bet on the correct answer and perhaps win money. In other systems, collective predictions on swarm platforms will take less than a minute. These low level-cognitive activities can often be done in combination with other activities (e.g., traveling to work or watching television) and it is important that they are perceived as interesting or entertaining.

Another issue is task variation. An individual might use most of the day to solve high-level cognitive challenges, and in the evening relax by doing some less cognitively demanding work on Mechanical Turk (Malone, 20 I 8: I94). Simple tasks can be motivated by an urge to fix incomplete work. The open display of errors in Wikipedia can trigger somebody to continue the work, for example by fixing spelling errors. Although bots do many of the minor fixes today, there is still a range of tasks that humans need to do.

\section{I4.2.2 Being Immersed in Complex Tasks}

In the $\mathrm{CI}$ projects that require advanced skills and a significant investment of time, it becomes more important to have a strong desire to solve the complex challenge and be passionate enough to sustain the effort over time. According to Levy (200I), programmers deeply appreciate the beauty of simple code that allow programs to perform complicated tasks. This esthetic motivation or individual flow keeps them going (Levy, 200I). When Linus Torvalds first created the Linux system, joy of the work was an important motivation (Himanen, 200I). Many solvers in online innovation contests also express positive feelings like enjoyment, excitement, fun, and pleasure (Hossain, 2018; Innocent et al., 2017).

In complex problem solving in online innovation contests, the economic rewards will usually not be sufficient to motivate participation because it is unlikely that one will win the prize money (Baltzersen 2020). 
Although, some activities may be both boring and tiresome, the long-term goal is associated with pleasure. For example, one top solver emphasizes the joy of working with very difficult challenges, "I'm always driven to the next difficult problem and I like difficult problems. I like the worst kinds of problems. I want the worst problems in the world in front of me. That's what I want to work on every time." When being immersed in a task, even the "worst kinds of problems" are experienced as motivating. Another solver emphasizes the positive feelings of being immersed in the collaborative work. It forces him to move out of his comfort zone because he is working with new people and unusual problems. Citizens who meet unknown others in citizen assemblies will probably have similar feelings when they are assigned to work together with strangers in solving societal problems.

In addition, solvers in online innovation teams are motivated by the constrained timeline and the competition between a few selected teams. It pushes the group to work harder, as one solver highlights:

Everyone knows that they are working side by side with us - and only the best team will win. Of course the money is also a motivation, but the award offered in almost all challenges is not enough, alone, to keep the team working. The intellectual challenge, the will to win is the springboard and the glue that keeps the team running.

The solver describes how the "will to win" is an important motivation that drives the challenge. The teams are motivated both by the difficulty of the challenge and the contest format.

\section{I4.3 Being Recognized}

An important individual motivation in many CI projects is to receive recognition for the work that has been done. Several projects aim to build motivation through different types of leaderboards and ranking systems. For example, Foldit provides a ranking system with high scores and individual ranking score on profile pages. The leaderboards are assumed to strengthen individual motivation through the joy of competing. In online innovation contests, some are motivated by the possibility of outperforming their peers:

It was nice to have an award and money for the time that I spent. But the emotion was more interesting of competing with other people and then being the successful team. That gives you a lot of confidence, a lot of motivation and this truly was much more important to me than the monetary reward. Especially as this was my area of expertise, so I should be doing well. 
The primary motivation is to be the most successful team; it is less about the prize money in itself.

In Topcoder, another innovation contest environment, part of the motivation is to test your own individual skills and compare them with the top community members. It is possible to track progress on the leaderboards. An overview of the personal ratings is displayed on each member's profile, covering skill areas within algorithm, design, and development. The open display of performance statistics on personal profile pages, such as in Topcoder and Foldit, suggest that several CI projects are also part of the new reputation society dominated by quantitative measurement models.

Likewise, IdeaConnection has ranking systems displaying how much prize money different solvers have won. The prize money is a quantitative recognition of their skills. When winning an award in an online innovation contest, some solvers interpret the prize money as an indicator of how much the work is valued, as one solver states, "It made me feel that what I know is appreciated and that even large and medium companies need outside advice."

Formal author recognition is another motivational factor. In some projects, amateurs receive scientific credit, but this is done differently. In Foldit, two teams (Void Crushers and the Contenders group) which made significant contributions were mentioned as coauthors on a paper with lead researcher Firas Khatib and other colleagues in 20 I I in the journal Natural Structural and Molecular Biology (C. Cooper, 2016: I 20). A group name is used and not the individual names of the persons in the group, suggesting that this is more of symbolic gesture as it is less important for amateurs to get scientific credit for their work. Likewise, research papers from the Polymath project are usually written under a pseudonym (e.g., "D.H.J. Polymath"). This can be a problem for early career mathematicians who may want to participate in a Polymath project, but who receive too little merit or acknowledgment for the work. Although they can learn much by participating in the project, they will often have to prioritize writing ordinary research papers instead (Michelucci \& Dickinson, 20I6; Tao, 20I4).

Using a list of authors can be another option, but in some cases, it will be difficult and time consuming to agree on the exact size of the individual contributions. Some may have done very little work. Still, Foldit researchers used a list of names to recognize amateur contributions in a recent scientific publication. More than one hundred players are mentioned by name at the end of the article (Horowitz et al., 20 I6). By giving 
scientific credit, this is one way of acknowledging the work of amateurs, which can perhaps strengthen their motivation.

Other amateurs are more motivated by being recognized in the working process. For example, in the Polymath project, amateurs are given the opportunity to work together with top mathematicians in the field. Some will be motivated by being in direct contact with famous scientists during the actual problem solving (Nielsen, 201 I).

Moreover, in Wikipedia, peers recognize each other by giving each other different types of awards. For example, a "barnstar" is an informal award that anyone can give to anyone as a recognition of that person's work in Wikipedia. These awards have a positive motivational effect on the most active Wikipedians (Benkler et al., 2015). Another study of Wikipedians show that it is not altruism but reciprocity and social image that are strong motives for sustaining cooperation (Algan et al., 2013). The motivational logic in relation to author recognition is very different, since active users are motivated if others reuse or modify their work. For example, in one study, a contributor was very proud because somebody had translated his work on one article into a similar article in another language edition of Wikipedia (Baltzersen \& Tolsby, 2008). It illustrates that peer recognition can manifest itself in several different ways. By contrast, if new contributors receive harsh treatment from experienced editors in Wikipedia, this will reduce the motivation to contribute (Benkler et al., 2015).

From one perspective, being recognized by peers is the same as receiving likes in social media. However, in CI projects, peer recognition is typically directed towards a substantial individual performance, and feedback from peers is usually sincere and honest. The use of likes in social media may be more casual, being part of a more detached "clicktivism culture."

\section{I4.4 Being Part of a Community}

Several CI projects show that active members feel a need to meet each other to experience that they belong to the same community. Active participants will often get new and more prominent roles in the community, like becoming Wikipedians or facilitators in innovation contest systems. In Topcoder, some of the participants who get new roles are motivated because they engage daily in community activities. As one of the crowd workers says: 
I feel Topcoder is an extension of my family right now, because I talk to members and Topcoder managers every day. It is like a real office for me. I spend the whole day talking about the project, challenge, and it is just for fun. Actually, the best friends that I already have are from Topcoder. They are from India, Romania, France, Italy. . . around the world. When I got started, I really liked this communication, because I felt I'm part of something. The communication of Topcoder, especially with the new members, is really good" $\left[\mathrm{P}_{7}\right]$. (Shafiei Gol et al., 2018)

The solver describes that they make friends from all over the world, and that it was like being part of an extended family. The close communication and friendships appear to be an important motivation for some of the highly skilled members who have core roles in the online community. Although Topcoder is built around contests, active members can still participate in ways that create a feeling of being part of a community (Shafiei Gol et al., 2018). There is also an increased awareness that it is important to offer a community space where members can interact and share ideas in between the competitions.

Long-term contributors will typically engage in social networks with others who share the same interest, including creative professionals (Brabham, 20I3: 68). In the online setting, the motivation will be to connect with other persons who share the same interest or hobby, and it will be less about having a similar background (age, gender, education) or living in geographical proximity. Part of the process of belonging to a community is about becoming acquainted with other like-minded people. This peer production brings together people who would otherwise not meet. Users will both be motivated to find their tribe (e.g., being connected with people who share their interests) and by becoming a hero (e.g., having a substantive positive impact on a community they care about) (Klein, 20I 2).

Opposite, social conflicts can be devastating for sustained participation. For example, one of the top contributors in Foldit over six years quit because of a falling out with another player and the management. He was part of the successful Contenders team and had no formal background within biology, but still managed to make substantial contributions to research. He had been playing Foldit almost every night for six years. On his user page, he shows that he became really upset when the management decided to support a teenager instead of himself who had been playing for 30,000 hours (C. Cooper, 2016: I 25). This example illustrates that when individuals join a project, they are first motivated by curiosity in science, but sustained activity is heavily influenced by social factors. It also 
illustrates the presence of an informal meritocracy in the player community, whereby player influence is based on player experience (C. Cooper, 20I6: I26).

Furthermore, CI projects that build on long-time work over many years will typically arrange regular large gatherings where people can meet in an offline setting (e.g., Wikimania conference, mapping parties). These gatherings are important for the most active contributors, such as the Wikipedians, who become acquainted with each other and strengthen their experience of belonging to the same community. Another example is how active OpenStreetMap contributors participate in so-called Mapping Parties. Here, contributors meet at a certain location, get to know each other, and share experiences about their work. The main events are the yearly "State of the Map" conferences, which are held at several different locations (Neis \& Zielstra, 2014).

In a study of a hackathon, the second most important reason to attend the hackathon was networking ( 82 percent), illustrating the importance of getting to know others and possibly learning something new from them (Briscoe \& Mulligan, 20I4). These meeting places are also important in that active members can acknowledge each other. The social contact is established through the shared interest in the work being done.

The importance of being part of a community is perhaps most evident in how many CI projects with weak community structures lose most contributors after a short time. When individuals work independently from each other, they feel alienated and more detached from the work. This makes it much easier to quit. Some of the simple citizen science projects that aim to collect independent individual judgements are vulnerable because there is less need for a community in the problem-solving process. A similar challenge is present in online systems that primarily crowdsource opinions through simple mass voting. One example is the Five Star Movement, which provides limited opportunity to deliberate, with the risk of reducing the motivation to participate. In other cases, like when somebody wants to modify an open textbook, the main goal is to make this process effective by removing the need to contact the original author (e.g., Creative Commons license).

Being part of a community can also be about branding. A video platform like YouTube still promotes itself as a community built upon authenticity, vernacular culture, and the accidental "viral" video star, even though most people are now realizing that it is all about business as usual. "Amateur content" is increasingly being produced by professional 
YouTubers in the attempt to maximize the number of subscribers or views to increase the cash flow (Burgess \& Green, 2018). Still, the success of YouTube illustrates how individuals can be motivated by wanting to be part of a "community" that is built around attractive community values.

What is interesting with Wikipedia is that individuals can be part of the community in many different ways. On one hand, an anonymous contributor can choose to improve an article without participating in any online discussion at all. On the other hand, the long-term volunteers are essential in the further development of the encyclopedia. They feel an ownership and commitment to make durable contributions and ensure that everyone follows the guidelines (Benkler et al., 20 I 5). However, most contributors will not be active Wikipedians, but they will still be very important in contributing to the different articles. Perhaps this flexible participation structure is key to the success of the Wikipedia community. If so, CI projects should build communities that allow for both loose and close engagement.

\subsection{Learning as Motivation}

Learning as motivation is an important motivational factor in many CI projects. Individuals who engage in collective problem solving will often experience being part of a learning process. In innovation contests, solvers know they can learn more by participating in a difficult challenge. For highly skilled workers, challenging work is essential to stay intrinsically motivated (Shafiei Gol et al., 2018).

\section{I4.5.I Individual Learning as Motivation}

In hackathons, one of the most important motivational factors is learning. In the context of software development, life-long learning is especially important because new technologies are invented at a rapid pace (Briscoe \& Mulligan, 20I4). Similarly, a solver participates in an innovation contest to update his professional skills, "I have a background in pharmaceuticals so I wanted to learn more about plants and the environment. I have not been associated with that field for quite a while and I've always had an interest in it. So it was a way to be re-introduced to what's going on in the field and it was really rewarding." This is not a formal way of learning, but instead it happens through problem solving. It illustrates that solvers sometimes choose to work with challenges in areas where they do not think they can win a prize, but where they will instead improve 
their professional skills (Hossain, 2018; Innocent et al., 20 I7; Shafiei Gol et al., 2018). Others join to get a better overview of the general problems in the industry. One solver emphasizes that innovation contests enable him to work on problems that are different from his ordinary work:

They allow me to work on tons of problems that normally you can't do when you're in a big company. You're not allowed to go down the hall and work on a problem with another group that's way outside of your group. So challenges allow me to work with people that I wouldn't normally get to work with and tackle problems that I wouldn't normally get to tackle.

The solver seeks out the problems he really wants to work with. In many CI projects, both passion towards the work and self-selection of tasks are important.

\section{I4.5.2 Collective Learning as Motivation}

In many CI projects, individuals will learn from each other in the collective problem-solving process. For example, in the IdeaRally, several solvers highlight the learning experience related to participating in a transparent environment (see Section 2.2). University students also participate in Topcoder competitions to learn from the reviewer feedback they receive on their proposed solutions. Even when the environment is centered on competition, members still discuss challenges and share ideas with each other in online forums. In addition, the final competitors get to see the designs and the codes of the other finalists. Part of the award is this access to others' work, since it motivates members to keep improving (Shafiei Gol et al., 2018). Because many contestants will not win prize money, learning is arguably the most important motivational factor.

Furthermore, most of the top solvers in the online innovation teams are motivated by the learning opportunities in the group (Baltzersen, 2020). One top solver describes how the diversity of the learning experience is an important motivational factor:

The best part was the opportunity to test ideas and lines of thought against others who have distinct experiences and approaches. If any idea is really good the others will adopt it, because the whole team will harvest the benefits. It the idea is bad, or if a team member is not able to present it in a good way, it will be rejected. Every idea accepted or rejected is a window to observe and learn how to be successful in a multicultural, competitive world. 
The solver highlights how one can learn something of all ideas, and "the best part" is to be able to test you own ideas and receive feedback from other, indicating that individuals with advanced skills are highly motivated by being in intense learning processes. Another solver underlines the value of meeting new people:

I enjoy the challenge of a new problem and it heightens and improves my skills, not only being challenged with new and different things around the world, but also meeting new people and learning how to deal with different personalities. So I'm learning in the process and giving back some of my skills to people who may benefit from them. That's one of my main motivations in life.

This solver appreciates the team process and learning how to deal with different personalities.

\section{I4.5.3 Transformative Learning as Motivation}

In some types of $\mathrm{CI}$, transformative learning can be a relevant motivational factor. Aida Berges, a contributor in the citizen science project Galaxy Zoo, is a 53-year-old stay-at-home mother of two living in Puerto Rico. She classifies hundreds of galaxies every week, and the work has changed her life forever: "it was like coming home for me." (Nielsen, 20 I I: I 55 ). The project gave her an opportunity to follow her passion. It illustrates the potential outreach in an online setting, and allows individuals to be part of projects that previously would not have possible because of geographical and social constraints.

Some CI systems like Topcoder attempt to retain solvers by designing promotion opportunities within the environment, whereby it is possible to become a reviewer. Solvers can build up a reputation which can be beneficial for their career opportunities. Long-time contributors become part of the Topcoder Veterans Community that supports individuals in moving into meaningful civilian jobs.

Another example is the Climate CoLab, which hopes to create attitudinal change by motivating people to create good ideas on how to fight climate change (Malone, 20 I 8) (see Section 2.2). Similarly, the increased use of citizen assemblies builds on the assumption that citizens will rise to the occasion when they are given responsibility. This will transform them into becoming more engaged citizens afterwards (see Section I 2.4). 


\section{I4.6 Economic Motivation}

Even in the direct democracy in ancient Athens, payment was essential in motivating participation. However, a juror only got three obols (Greek currency) for one meeting, which lasted a whole day. This was far less than a day's wage, but it might have been the only chance for some groups to earn anything at all. The payment was enough to meet the necessities of a small family, and for the elderly, the invalid, and the unemployed. Many jurors were probably older citizens who could no longer do hard physical work, but they were still able to listen to speeches. Still, the payment appears to have been sufficient to ensure that enough qualified people turned up for allotment (Hansen, I991: I83-I89).

If we look at how the deliberative tasks are organized today, citizens also often receive an honorarium. For example, both the Deliberative Polling in Mongolia and the Citizens' Council in Ostbelgien give some payment and cover participants' costs. However, since the work is considered a civic duty, pay as an extrinsic motivation is not supposed to be important. Still, it may be essential in recruiting individuals from low-income groups.

In this book, it is primarily innovation contests that use economic rewards to motivate participation. Some successful solvers even regard this type of activity as full-time work, but the majority look at prize money as an extra bonus income (Baltzersen, 2020). The reward models are also different. Online contests such as IdeaConnection and Innocentive often give a large amount of money to a few winner solutions. The others get nothing. Because the challenge requires skilled expertise and because the likelihood of winning is relatively small, it is important that the size of the prize is big. In the team contests, the chances of winning is much larger, since only a few teams compete against each other. In contrast, the Topcoder model is different, as the rewards for IT challenges are often modularized into minor payments. In addition, timely and guaranteed payment is important because there are no traditional employment contracts or benefits (e.g., healthcare). The competition and selection of winners must be perceived as fair and transparent (Shafiei Gol et al., 2018).

Another important motivational factor in CI projects is self-selection of tasks. Freelancers will want to control their working hours and only register for contests that match the person's skill or interest (Shafiei Gol et al., 20I8). It is also important that the solvers are able to find the appropriate challenges quickly. In general, these types of environment encourage hyperspecializaton. For example, somebody who is particularly good at designing user interfaces can do just that. When workers get to 
choose the tasks they want to do, it increases the likelihood of finding people who are really good at doing the tasks (Malone, 2018: 19I, 195).

Another economic motivation is that the participation can strengthen career opportunities. By earning money, doing different kinds of work, learning new skills, and earning a rating, one can build a portfolio or $\mathrm{CV}$ that is relevant for future employment. Some technology companies even recruit persons directly from sites like Topcoder. In addition, many regard participation in the innovation contest environment as a new of doing professional networking (Arnold, 2019c).

Online communities struggle if they do not offer any career tracks. One example is the qwiki that was established by John Stockton in 2005 . Inspired by the Wikipedia model, the goal was to invite researchers to develop the best collective resource on quantum computing. The resources would be constantly updated and cover material ranging from simple introductions of key concepts to detailed explanations of the latest research, including source materials, animations, and interactive simulations. There were high hopes of a new wiki science. Many professional scientists were also invited to join the work, but very few did any work at all. The majority of the few users who joined the project spent most of their time writing about their own research on the profile page. Most of them believed the potential was tremendous, but still none were willing to spend any time. After six years the project eventually stopped. Ambitious scientists were forced to pursue scientific publications and research grants. Moreover, the young scientists had to do the same, in the tough competitive environment of securing a scientific job. The science wiki did not provide enough scientific merit and offered no prosperous future careers. Wiki-science remains an unrealized dream (Nielsen, 20 I I: I76-I79).

\section{I4.7 Making Societal Contributions}

In ancient Athens, every citizen who had sworn the Heliastic oath was equipped with a personal "ticket." It was a small bronze plaque, inscribed with the individual's full name and mostly stamped (Figure I4.I). This citizen token or pinaikon served the function of being an "identity paper," and it was used in the lottery machines in the People's Court. Detailed study of most of the surviving plaques shows that the name of the original holder has been hammered out and replaced with another name. The plaques changed hands often because the composition of the 6,000 jurors changed annually. It indicates a competition for places to become a juror. 


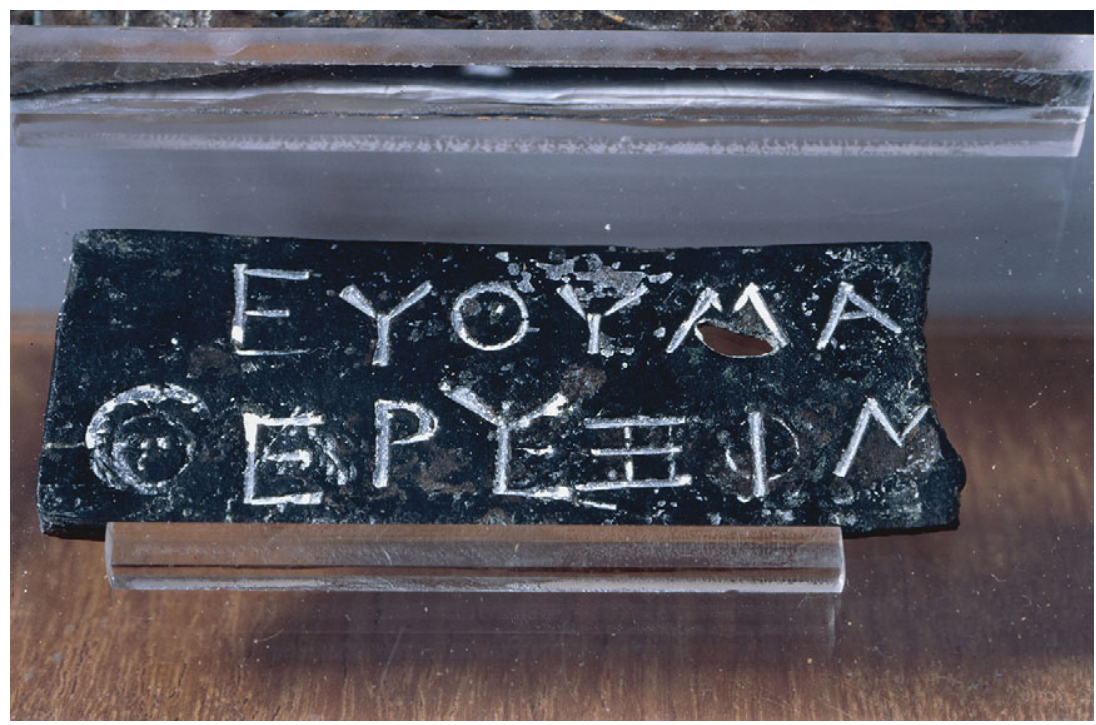

Figure I 4. I A juror identity card or pinakia identifying citizen by names. Clay fragment with Greek inscription, fourth century BC. The identity cards list the name of the juror,

his father, and that of his area (demos). When selecting jurors by lot, these plates or "identity tokens" were inserted into the kleroterion, the randomization machine.

This fragment is located in the museum of the Ancient Agora, Athens. Photo John Hios/Akg-images/NTB

But what is most striking is that all the best-preserved plaques have been found in graves. It is a testimony to the unique mentality in Athens in this period, because in archaic times, most citizens would want weapons, not small plaques, in their grave (Hansen, I991: I8 I-I 82). It illustrates how proud the Athenians were of their democratic system and the opportunity to make societal contributions.

Other successful CI projects build on a similar to have a positive influence on society. A top solver in an innovation contest is proud of winning a contest: "Being a winner was a reason of pride with the feeling to have provided important ideas to solve important problems." Although some of the CI projects require simple "boring" work, these persons may still be motivated because of the societal value of their work. A study of Galaxy Zoo, a citizen science project, found that the most important volunteer motivation is the opportunity to contribute to research, regardless of gender or age (Raddick et al., 2013). In large projects like Wikipedia, some of the simple "cleaning work" and moderator work done 
by Wikipedians will be important in maintaining the encyclopedia to a high quality. These individuals feel a strong sense of civic duty (B. Stewart $\& \mathrm{Ju}, 2020)$.

According to Himanen (200I), the motivation among coders (hacker ethic) is passion or the desire to create something valuable together with others. Hackers believe that everyone in society should be able to interact with computers in the same way, since computers have opened up a world of opportunities that could potentially create better lives for people (Levy, 200I). Himanen (200I) emphasizes that these volunteers want to create something valuable for the community that shares their passion. Individual work is shared with the community so it can stimulate further knowledge development. In the political domain, it is interesting how both vTaiwan and Better Reykjavík emerge from this type of hacker philosophy. Even the Five Star Movement was founded on the concept of involving citizens in new ways of political life.

Today, this philosophy is present when amateurs share videos of their hobbies on how to solve different practical tasks. Individuals who are passionate about their skills and knowledge will often want to share them with a wider community. Instructional videos have a societal value, and the producers may also receive acknowledgment through views, likes, and comments from other like-minded people on the Internet. On an aggregated level, all this work helps to strengthen our human collective memory, but at an individual level, it is about sharing and being generous.

Although some individuals participate in projects to earn money, the large majority participate because they have extra free time. The basic requirement is "cognitive surplus," a term used to characterize the extra free time we have in addition to the basic obligations of life, like doing paid work or spending time with our family. It usually involves different leisure activities like being together with friends or doing a hobby. There are wide ranges of projects one can join, depending on the background skills. Several projects require specific skills and a significant level of individual expertise. The projects range from tasks that require no expertise (e.g., Galaxy Zoo), some level of expertise (e.g., Wikipedia) to advanced levels of expertise (e.g., IdeaConnection). The amount of time required also differs, from minutes (e.g., Galaxy Zoo) to months or years (e.g., Polymath). In complex challenges like innovation contests, solvers have to be available a considerable amount of time within a period of weeks. In contrast, very little effort will be required if you rate or comment on a published video. In work requiring some level of effort, most individuals participate because they are passionate about the work 
they are doing. This includes both low-level challenges (e.g., Galaxy Zoo) that require little time and more time-demanding high-level challenges (e.g., innovation contest).

Retirees is an example of an age group that have new opportunities to continue working. For example, a senior solver still participates in online innovation contests:

I love the challenge of a problem as it keeps my mind busy. I think I'm as creative as I ever was, and probably even more creative than I ever was, and I'm now seventy years old. It's the stimulus that folk like Idea Connection provide for me to do that. If companies such as IdeaConnection weren't around it might have been more difficult for people like me to find an outlet for our creative energies.

These contests are important because they are an "outlet for creative energies." This type of online work is not only good use of human resources in society, but it also enriches personal lives. It is attractive for both companies and the solvers, but one should note that these case stories only report from a tiny group of highly competent professionals. Even in citizen science projects that require relatively simple work, the volunteers are more educated than the average population, and the majority are middle-aged or old white men (Raddick et al., 2013). Still, the examples point to new opportunities for a more flexible type of crowd work.

\section{I4.8 Summary}

The specific mix of motivational factors used in the design of a CI project depend on the type of person one wants to recruit. Obviously, there is a major difference between recruiting people to make small and simple micro-contributions and motivating highly skilled persons to spend a lot of time and work to solve a problem. In many CI projects, it will be important to design a community that can recruit a group of people that have different motivations. Table I4.I gives an overview of the characteristics of different motivational factors that are relevant to CI projects.

In many cases, several of the abovementioned facts will motivate individuals. While some CI projects are clearly built around an online community (e.g., Wikipedia), other CI projects center on contests and short-term involvement in specific problems. It is more uncertain whether online communities can be successful in the long run without having any offline meeting places. In Wikipedia, contributions will require both simple and advanced skills. Therefore, it is important to design a 
Table I 4. I. An overview of different motivational factors relevant to $C I$

\begin{tabular}{|c|c|}
\hline Motivational factors & Characteristics \\
\hline $\begin{array}{l}\text { I. Being } \\
\text { immersed }\end{array}$ & $\begin{array}{l}\text { - Simple tasks (high cognitive level) that require little effort. Be } \\
\text { fun or relieve boredom (e.g., image detection in citizen science, } \\
\text { proofreading in Wikipedia). } \\
\text { - Advanced tasks (low cognitive level). Developing new ideas } \\
\text { through intense work, like time-limited work in innovation } \\
\text { contests or a Citizens' Assembly. }\end{array}$ \\
\hline 2. Being recognized & $\begin{array}{l}\text { - Active contributors want to be recognized by their peers (e.g., } \\
\text { Wikipedians). } \\
\text { - Author recognition. } \\
\text { - Positive feedback from prominent peer members. } \\
\text { - Peer recognition through leaderboards. }\end{array}$ \\
\hline $\begin{array}{l}\text { 3. Being part of a } \\
\text { community }\end{array}$ & $\begin{array}{l}\text { - Active participants will be part of a community, involving both } \\
\text { citizen science (Foldit) knowledge sharing (Wikipedia) and } \\
\text { online innovation contests (Topcoder). } \\
\text { - Active participation in offline setting (e.g., Wikimania, mapping } \\
\text { parties, Citizens' Assembly). } \\
\text { - Flexible participation that also allows some individuals to make } \\
\text { anonymous separate contributions. }\end{array}$ \\
\hline $\begin{array}{l}\text { 4. Learning } \\
\text { as motivation }\end{array}$ & $\begin{array}{l}\text { - Individual learning: (e.g., innovation contest like Topcoder, } \\
\text { Citizens' Assembly) } \\
\text { - Collective learning: Learning from others in transparent } \\
\text { environments and through discussions (e.g., IdeaRally, crowd } \\
\text { peer review, online teams in innovation contests, Citizens' } \\
\text { Assembly) } \\
\text { - Transformative learning: (e.g., becoming a citizen scientist, } \\
\text { innovation contest winner, or Wikipedian). }\end{array}$ \\
\hline $\begin{array}{l}\text { 5. Economic } \\
\text { motivation }\end{array}$ & $\begin{array}{l}\text { - Payment, rewards, and prize money. } \\
\text { - Providing future career opportunities (e.g., profiles pages that } \\
\text { display your work, develop portfolio for future employment). } \\
\text { - Flexible participation. Work autonomy and self-selection of } \\
\text { tasks according to your own interest and competence. } \\
\text { - Trusting the system. Safety becomes more important when } \\
\text { commitment is higher (payment, personal security, } \\
\text { employment). }\end{array}$ \\
\hline $\begin{array}{l}\text { 6. Making } \\
\text { societal } \\
\text { contributions }\end{array}$ & $\begin{array}{l}\text { - Utilize all human resources in society in both political and } \\
\text { scientific domain. } \\
\text { - People living in remote areas can work in an online setting. } \\
\text { - Proud of doing important work (e.g., participatory governance } \\
\text { in Citizens' Assembly, innovation contest, citizen science, } \\
\text { sharing passion). }\end{array}$ \\
\hline
\end{tabular}


community where peers recognize and honor each other. The examples from the innovation contests illustrate how solvers can both be motivated by economic rewards and intrinsic motivational factors such as being immersed in the task. Solvers are also motivated because they learn through participation, being passionate about both the collective problem solving and the opportunity to make societal contributions. In some cases, like in innovation contests, there is a trade-off between competitive structures that privatize the knowledge production and the community structures that facilitate open knowledge sharing. 